\title{
Impact on Society Due to DhatSyndrome
}

\author{
Dr. Manju Bhaskar ${ }^{1}$,Dr. RajinderPal Singh ${ }^{2}$,Dr. Rishika Agarwal ${ }^{3}$,Dr. Kuldeep \\ Singh Yadav ${ }^{4}$. \\ ${ }^{1}$ Assistant Professor, Department Of Psychiatry Mahatma Gandhi Medical College, Jaipur \\ 2. Senior Resident, IHBAS, Delhi \\ ${ }^{3}$ Junior Resident, Department Of Psychiatry Mahatma Gandhi Medical College, Jaipur \\ ${ }^{4}$ Senior Resident, SMS Medical College, Jaipur.
}

\section{Introduction}

Cultural beliefs prevalent in the society have a very severe impact on the mind and behavior of the person. There are many misbeliefs and misconceptions about sexuality prevalent in our society. Many cultures believe semen to be a very precious body fluid and its unnecessary loss to cause severe harm on the health of the person. ${ }^{1}$ Cultural myths in relation to semen loss can induce physical and psychological symptoms in a man which together as a syndrome termed as Dhat syndrome. "Dhat" is derived from the word "dhatu". The word "Dhatu" is a Sanskrit word which means "Metal" or "Elixir". ${ }^{2-4}$ There is description of seven "Dhatus" [Chyle (Rasa), Blood (Rakta), Flesh (Maans), Fat (Meda), Bone (Asthi), Marrow (Majja), Se-men (Shukra)], out of which most important considered is "Shukra Dhatu (semen)".

Dhat syndrome is described as a culture bound syndrome (CBS). There is an ongoing debate on the nosological status of CBS. Dhat syndrome has been found to be prevalent in different geographical regions of the world. It has been described in literature from China, Europe, Americas, and Russia at different points of time in history. Mention of semen as a "soul substance" could be found in the works of Galen and Aristotle who have explained the physical and psychological features associated with its loss. ${ }^{5}$

The assumption that these cultures bound syndromes affect only specific cultures have resulted in limiting global interest in understanding these conditions and their management.

So, in our study, we tried tofind out impact of dhat syndrome on person's daily living, health, surroundings, their professional life and on the society.

\section{Material And Methodology}

The study was conducted in Department Psychiatry, Mahatma Gandhi Medical College and Hospital, Jaipur, Rajasthan. The study was approved by the ethical committee of the institution. The study included 100 patients who presented in the Psychiatry OPD with the primary complaint of involuntary discharge of semen. Informed consent was taken from all the patients before including them in the study.

The patients were enquired about their demographic profile (like age, marital status, educational status, occupation, socio-economic status, family details). They were specifically asked about their personal life like their sexual history, drug abuse, alcohol and smoking. They were enquired about their primary complaint of Dhat, timings of discharge, associated health problems or any sexual problem.

Then the responses were recorded as - never, regular sometimes. Data was collected and Statistical analyses were performed using the Statistical Package for the Social Science Version (SPSS). Descriptive analysis were analyzed in terms of mean and standard deviation for variables. Fre-quency was used for nominal variables with percentage.

Table 1 - Socio-demographic Data

\begin{tabular}{|c|c|c|}
\hline Variables & $\mathrm{N}(100)$ & $\%$ \\
\hline \multicolumn{3}{|c|}{ - $\quad$ Age (yrs) } \\
\hline \multirow{4}{*}{$\begin{array}{l}18-28 \\
29-38 \\
39-48 \\
>49\end{array}$} & 60 & 60 \\
\hline & 10 & 10 \\
\hline & 25 & 25 \\
\hline & 5 & 5 \\
\hline \multicolumn{3}{|c|}{ - $\quad$ Previousy ever had sex } \\
\hline \multirow{2}{*}{$\begin{array}{l}\text { Yes } \\
\text { No }\end{array}$} & 40 & 40 \\
\hline & 60 & 60 \\
\hline \multicolumn{3}{|c|}{ • Marital status } \\
\hline \multirow{3}{*}{$\begin{array}{l}\text { Married } \\
\text { Unmarried } \\
\text { Separated }\end{array}$} & 20 & 20 \\
\hline & 70 & 70 \\
\hline & 10 & 10 \\
\hline
\end{tabular}




\begin{tabular}{|c|c|c|}
\hline \multirow{2}{*}{$\begin{array}{cc}\bullet & \text { Type of Family } \\
\text { Nuclear } & \end{array}$} & & \\
\hline & 30 & 30 \\
\hline \multirow{2}{*}{$\begin{array}{l}\text { Joint } \\
\text { Alone }\end{array}$} & 15 & 15 \\
\hline & 55 & 55 \\
\hline \multicolumn{3}{|l|}{ - Education } \\
\hline \multirow{4}{*}{$\begin{array}{l}\text { Illiterate } \\
\text { Up to } 10 \text { th } \\
\text { Up to Graduate } \\
\text { Above Graduate }\end{array}$} & 23 & 23 \\
\hline & 27 & 27 \\
\hline & 44 & 44 \\
\hline & 6 & 6 \\
\hline \multirow{6}{*}{$\begin{array}{l}\quad \bullet \quad \text { Occupation } \\
\text { Unemployed/ Student } \\
\text { Unskilled worker } \\
\text { Skillled worker } \\
\text { Clerical worker } \\
\text { Professional }\end{array}$} & & \\
\hline & 49 & 49 \\
\hline & 20 & 20 \\
\hline & 18 & 18 \\
\hline & 8 & 8 \\
\hline & 5 & 5 \\
\hline \multirow{3}{*}{$\begin{array}{ll}\bullet & \text { Residence } \\
\text { Rural } & \\
\text { Urban } & \\
\end{array}$} & & \\
\hline & 64 & 64 \\
\hline & 36 & 36 \\
\hline \multirow{3}{*}{$\begin{array}{ll} & \bullet \\
\text { Yes } \\
\text { No }\end{array}$} & & \\
\hline & 54 & 54 \\
\hline & 46 & 46 \\
\hline \multirow{4}{*}{$\begin{array}{l}\quad \bullet \quad \text { Aloc } \\
\text { Regular } \\
\text { Occasional } \\
\text { Never }\end{array}$} & & \\
\hline & 20 & 20 \\
\hline & 46 & 46 \\
\hline & 34 & 34 \\
\hline \multirow{3}{*}{ 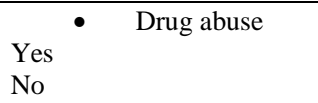 } & & \\
\hline & 20 & 20 \\
\hline & 80 & 80 \\
\hline
\end{tabular}

Table 2 - Clinical profile of the patients ${ }^{1}$

\begin{tabular}{|l|l|l|}
\hline Duration of suffering & \multicolumn{1}{|c|}{$\mathrm{N}$} & Percentage (\%) \\
\hline <6months & 10 & 10 \\
\hline 6months-1year & 20 & 20 \\
\hline$>$ 1 year & 70 & 70 \\
\hline & & \\
\hline Frequency of passage of dhat & & \\
\hline Everyday & 20 & 20 \\
\hline Every week & 66 & 66 \\
\hline Once a while & 14 & 14 \\
\hline & & \\
\hline When they have passage of dhat* & & \\
\hline While passing urine & 70 & 70 \\
\hline While straining for passing stools & 10 & 10 \\
\hline During sleep & 50 & 50 \\
\hline While sexual excitement & 40 & 40 \\
\hline Anytime & 25 & 25 \\
\hline & & \\
\hline What they have done till now for this & & \\
\hline Nothing & 70 & 70 \\
\hline Consulted quacks & 20 & 20 \\
\hline Consulted doctors & 10 & 10 \\
\hline & & \\
\hline $\begin{array}{l}\text { Any associated sexual complaint reported by } \\
\text { patients* }\end{array}$ & & \\
\hline Erectile dysfunction & 10 & 10 \\
\hline Premature ejaculation & 75 & 5 \\
\hline Masturbation & 35 & 35 \\
\hline Thin semen & 5 & 5 \\
\hline Small penis & 10 & 10 \\
\hline No other sex related symptoms & & \\
\hline & & \\
\hline Any associated health problem & & \\
\hline
\end{tabular}




\begin{tabular}{|l|l|l|}
\hline patient* & & \\
\hline Constipation & 65 & 65 \\
\hline Generalized weakness & 90 & 90 \\
\hline Insomnia & 45 & 45 \\
\hline Body ache & 40 & 40 \\
\hline Anxiety & 60 & 60 \\
\hline Burning micturition & 10 & 10 \\
\hline No refer to any other associated health problem & 2 & 2 \\
\hline
\end{tabular}

* A patient can have more than one response

Response of the patients to questions asked to find the impact of their suffering of dhat on their daily living, their health, their family and surroundings, their professional life and the society:

Table 3

\begin{tabular}{|llll|}
\hline During the past week, did they feel: & Never & Sometimes & Regular \\
\hline & $\mathrm{N}(\%)$ & $\mathrm{N}(\%)$ & $\mathrm{N}(\%)$ \\
\hline Lack of energy? & 0 & 30 & 70 \\
\hline Disturbed sleep? & 14 & 52 & 34 \\
\hline Somatic symptoms like bodyache, fainting, dizziness? & 14 & 41 & 45 \\
\hline No interest in work \& surroundings? & 14 & 35 & 51 \\
\hline Not able to enjoy anything. & 20 & 40 & 40 \\
\hline Feel of inferiority complex. & 20 & 23 & 57 \\
\hline Feel life is meaningless \& worthless. & 20 & 50 & 30 \\
\hline Think its better to die. & 34 & 45 & 21 \\
\hline Decreased apetite. & 20 & 30 & 50 \\
\hline Crying spells. & 14 & 34 & 52 \\
\hline
\end{tabular}

\section{Results}

Assessment of demographic profile of Patients (as shown in Table 1) The study included 100 male patients presenting with Dhat syndrome. The mean age of study sample was 25 years with an age range of 18-59 years. The most affected age group was of $18-28$ years which constituted about $60 \%$ of patients, about $10 \%$ were in the age range of 29-38 years, 5\% patients were aged above 49 years.More than two-third of the patients were unmarried, the rest were married $(20 \%)$ or living separated $(10 \%)$. The condition had a high prevalence in educated population, about $44 \%$ of patients were graduate or above. Most of the patients were either unemployed or student $(49 \%)$. The condition was prevalent more in rural community with about $64 \%$ patients belonging to rural areas. Dhat syndrome was more found in people who were living alone (55\%) or in nuclear family as compared to joint family $(15 \%)$ and in people who had no previous history of having sex (60\%).Occasional alcoholics had higher incidence $46 \%$ as compared to sobers, but uncommon in drug abusers. $54 \%$ were found to be smokers and $20 \%$ were drug abusers.

Assessment of clinical profile of the patients is shown in Table 2. The mean duration of symptoms at the time of presentation was $>1 \mathrm{yr}$., and nearly $66 \%$ patients were passing dhat every week while $20 \%$ of patients were passing dhat at least once in a day. Most of the patients complained of passage of dhat while urination(70\%). Majority of patients(70\%) have not consulted anyone while about $20 \%$ have consulted quacks. When asked about associated sexual complaints, about $75 \%$ were worried about their habit of masturbation. $35 \%$ reported that their semen is thin and about 10\% reported erectile dysfunction. Most of the patients reported generalized weakness, $65 \%$ patients had constipation and about $10 \%$ complained of burning micturition.

Impact on society: It is clear from the response of patients to the questions asked, that dhat syndrome had severe impact on their daily living, their health, their surroundings, their professional life and the society (Table 3). Most patients have regularly no interest in work or their surroundings. About all the patents feel lack of energy and most of the patients had disturbed sleep and somatic symptoms like bodyache, fainting, dizziness. About half of patients regularly remain irritable and have frequent crying spells. Majority number of patients thought that everything is meaningless, feel life is not worthwhile and even wish they were dead.

\section{Discussion}

Dhat syndrome, although described as culture bound syndrome, has been found to be prevalent in different geographical regions of the world and has been found to be emerging in other countries as well. A significant number of patients with dhat syndrome come to urologist consultation but there have been very limited reports that describe or analyse this syndrome in urological literature. ${ }^{6}$ In the case of dhat syndrome, the nature of underlying belief, i.e., semen is the most vital fluid and has to be conserved at any cost ${ }^{\circ}$ is such that there is intense distress in the wake of continued loss of dhat. ${ }^{7}$ Sumathipala et $\mathrm{al}^{8}$ and Balhara et al ${ }^{9}$ have reported that dhat syndrome was not confined to Oriental countries infact it was prevalent in Europe, USA and Australia in the nineteenth century. 
In our study, we found that dhat syndrome is mainly seen in particular strata of population: young males living alone or in nuclear family, with low income, more commonly in rural community and common in both illiterate and educated men. Few previous studies conducted by Chaddha et $\mathrm{al}^{10}$, Grover $\mathrm{S}$ et $\mathrm{al}^{11}$ and Gautam $M$ et $a^{12}$ reported that patients complaining of Dhat Syndrome are typically more likely to be young people, who are recently married or single; of average or low socio-economic status, coming from a rural area and belonging to a family with conservative attitudes towards sex while a study conducted by Verma $\mathrm{R}$ et al ${ }^{13}$ reported more prevalence from urban area.

In our study, the mean duration of symptoms at the time of presentation was $>1 \mathrm{yr}$, and nearly $66 \%$ patients were passing dhat every week while $20 \%$ of patients were passing it at least once in a day. In a recent study, conducted in Spain ${ }^{9}, 25 \%$ of patients complained of daily sperm loss while in $37.5 \%$ it was weekly and patients complained of the syndrome lasting from 3 months up to 10 years. In a study conducted ${ }^{14}$ complaint of duration of the semen loss lasts up to 20 years. As reported by Grover $\mathrm{S}$ et a ${ }^{15}$ and Rajkumar R et $a{ }^{16}$ showed that patient complaining of passage of dhat also complains of various somatic symptoms most common being generalized weakness $(86.4 \%)$ and constipation $(59.1 \%)$ and also some irrelevant sex related problems like fear of thin semen or small penis.

Most of the patients believed that they are losing semen in dhat and more than half of patients consider this to be a consequence of their habit of masturbation. Infact their self guilt of masturbation due to the misconceptions prevalent in the society lead to these false attributes. ${ }^{17}$

They are so much threatened by the misbeliefs in the society that they believe that they will get very weak and will not be able to do sex or bear child. ${ }^{1}$ Due to these fears their physical and mental health; and personal and social life get so much disturbed as clearly shown by our study that they lose all their interest in their work, their surroundings and have a feel of fear and tiredness. ${ }^{1}$ Various treatment strategies have been recommended with varying results in the literature.

Avasthi $\mathrm{A} \mathrm{et} a \mathrm{l}^{18}$ had advised a standardized treatment protocol that mainly includes sex education, biofeedback and relaxation exercises.

\section{Conclusion}

The results of our study clearly showed that dhat syndrome have a severe impact on the physical, mental and social health of the patient as a whole. This condition is more common in a specific strata of population mainly young people living alone or nuclear families having low income, more common in rural areas but also prevalent in urban areas, both illiterate as well as well educated men. ${ }^{24}$ Also counseling, correction of misbeliefs, along with sex education and reassurance alone brings dramatic improvement in the physical, mental and social health of the patient. So sex education should also be incorporated in our education system.and counseling camps should be organized focusing to predisposed population. ${ }^{24}$

\section{References}

[1]. Verma A, Priyadarshi S, TomarV.Analysis of Patients Presenting with Dhat Syndrome and its Impact on Society.IJSR4(12), December 2015;982-987.

[2]. Prakash O. Lessons for postgraduate trainees about Dhat syndrome. Indian J Psychiatry 2007;49:208-10

[3]. Shushruta S. Vaidya YadavjiTikamjiAcharya.Bombay:NirnayaSagar Press; 1938.

[4]. Money J, Prakasam KS, Joshi VN. Semen-conservation doctrine from ancient ayurvedic to modern sexology theory. Am J Psychother 1991;45:9-13.

[5]. Koushik Sinha Deb, Yatan Pal Singh Balhara. Dhat Syndrome: A Review of the World Literature. Indian J Psychol Med. 2013 OctDec; 35(4): 326-331.

[6]. Menendez .V, Fernández-Suárez A, Placer J, GarcíaLinares M, Tarragon S, Liso E. Dhat syndrome, an emergent condition within urology in Spain. World J Urol 2013;31:941-5

[7]. Prakash S, Sharan P, Sood M. A study on phenomenology of dhat syndrome in men, New Delhi (Thesis submitted to the faculty of All India Institute of Medical Sciences); 2012.

[8]. Sumathipala A, Siribaddana SH, BhugraD.Culturebound syndromes: the story of dhat syndrome. Br J Psychiatry 2004;184:200-9

[9]. Balhara Y. Culture-bound syndrome: Has it found its right niche? Indian J Psychol Med 2011;33:210-5.

[10]. Chadha C, Ahuja N. Dhat syndrome. A sex neurosis of the Indian subcontinent. Br J Psychiatry 1990;156:577-9

[11]. Grover S, Avasthi A, Aneja J, Shankar G, Mohan M R, Nehra R et al. Comprehensive Questionnaire for Assessment of Dhat Syndrome: Development and Use in Patient Population. J Sex Med 2014;11:2485-95

[12]. Gautam M, Singh R, Weiss H, Brugha R, Patel V, Desai NG et al. Socio-cultural, psychosexual and biomedical factors associated with genital symptoms experienced by men in rural India. Tropical Medicine and International Health 2008;13:384-95

[13]. Verma R, Mina S, Hassan S, Balhara YPS. A Descriptive Analysis of Patients Presenting to Psychosexual Clinic at a Tertiary Care Center. Indian Journal of Psychological Medicine 2013;35:241-7.

[14]. De Silva P, Dissanayake SA. The loss of semen syndrome in Sri Lanka: a clinical study. Sex Marital Ther 1989; 4:195-204

[15]. Grover S, Avasthi A, Gupta S, Dan A, Neoqi R, Behere PB et al. Phenomenology and beliefs of patients with Dhat syndrome: A nationwide multicentric study. International Journal of Social Psychiatry 2015.

[16]. Rajkumar R. Dhat syndrome: Evidence for a depressive spectrum subtype. Asian Journal of Psychiatry 2014;9: 57-60

[17]. El Hamad I, Scarcella C, Pezzoli MC, Bergamaschi V, Castelli F. Forty meals for a drop of blood. J Travel Med 2009;16:64-5

[18]. Avasthi A, Gupta N. Standardised management of single males with sexual disorders. Marital and Psychosexual Clinic Department of Psychiatry, PGIMER, Chandigarh.2002 